\section{What Fibrinolytic Therapy can Learn from Natural Fibri- nolysis: Both Activators are a Requirement}

\section{Victor Gurewich*}

Vascular Research Laboratory, Mount Auburn Hospital, Cambridge, Harvard Medical School, USA

\section{Abstract}

Fibrinolytic therapy with tissue Plasminogen Activator (tPA) alone has been the standard for three decades, but due to its inefficacy and bleeding risk, tPA has been replaced by Primary Percutaneous Coronary Intervention (PPCl) as the treatment of choice for Acute Myocardial Infarction (AMI). By contrast to tPA mono-therapy, natural fibrinolysis uses a sequential combination of both biological activators, tPA and uPA, the native form of which is a proenzyme, prouPA. Both in vitro and in vivo, IPA and prouPA have complementary modes of action in fibrinolysis are synergistic when combined. In a published clinical trial, the patent study, 101 patients with AMI were treated with a $5 \mathrm{mg}$ tPA bolus ( $5 \%$ of the standard monotherapy dose) followed by a modest infusion of prouPA. This sequential combination virtually doubled the coronary TIMI-3 infarct artery patency rate and reduced the mortality six-fold compared to the best results with tPA alone.
\end{abstract}

\section{Introduction}

Fibrinolysis is the body's natural defense that prevents physiological fibrin, needed for the repair of wear and tear vascular injuries, from building up and interfering with blood flow. Evidence that this system is functioning comes from the invariable presence of

*Corresponding author: Victor Gurewich, Vascular Research Laboratory, Harvard Medical School, USA, Tel: +617 661 0567; Email: vgurewich@tsillc.net

Citation: Gurewich V (2018) What Fibrinolytic Therapy can Learn from Natural Fibrinolysis: Both Activators are a Requirement. J Non Invasive Vasc Invest 3: 010.

Received: February 20, 2018; Accepted: May 21, 2018; Published: June 05, 2018

Copyright: () 2018 Moshaand SS, et al. This is an open-access article distributed under the terms of the Creative Commons Attribution License, which permits unrestricted use, distribution, and reproduction in any medium, provided the original author and source are credited. the fibrinolytic degradation product D-dimer in plasma (110-250 ng/ $\mathrm{ml})$. Therapy with tPA alone was believed to the biological pathway. However, this idea represented a fundamental misunderstanding of the biological system, which remains to be addressed [1]. Ever since the FDA approved tPA for the treatment of AMI I 1987, it has been the activator choice. However, the body has two plasminogen activators, the second one being urokinase Plasminogen Activator (uPA), the native form of which is a proenzyme (prouPA) [2]. Since both are required for an effective and safe fibrinolytic effect, the full potential of fibrinolytic therapy has never been evaluated.

\section{Discussion}

The fibrinolytic clinical experience has been with tPA monotherapy almost exclusively and this has been sufficiently disappointing that fibrinolysis has become discredited. Primary Coronary Intervention (PPCI) is now the treatment of choice for AMI. For ischemic stroke, the tPA bleeding risk is higher and has obliged a one third tPA dose reduction which further diminished its efficacy. Even with this reduction, a 7\% risk of intracranial hemorrhage remains [3]. Due to this risk, reperfusion therapy must be delayed until a careful history and diagnostic studies have eliminated a bleeding risk or intracranial bleed. Because of these risks tPA remains "mired in controversy." A more effective and safer fibrinolytic is, therefore, particularly urgently needed for ischemic stroke.

Although PPCI is the uncontested treatment for AMI, it is handicapped by being a hospital procedure that is time-consuming, technically demanding, and costly. This limits the patient population that can be adequately served. In addition, optimal results are time-dependent. Reduction in AMI mortality is greatest when reperfusion is accomplished within 1-2 hours of the event [4]. When it can be done within 70 minutes, the mortality was $1.2 \%$ [5]. Similarly, in animal models the longer the coronary occlusion, the less salvageable myocardium remains [6]. This places geographic limitations on treatment.

Therefore, in not only for stroke but also for many AMI patients a better fibrinolytic is needed. Since these are among the commonest causes of morbidity and mortality worldwide, for the majority of patients only more effective and safer fibrinolysis can provide sufficiently timely reperfusion.

The endogenous fibrinolytic system uses not one activator but two. Fibrinolysis is initiated by tPA when it is released from the vessel wall at the site of a fibrin clot. The tPA binds to the clot at its fibrin binding site on the D-domain of fibrin and activates plasminogen on the same domain fibrin $[7,8]$. The unbound tPA is then promptly cleared by its short $(5 \mathrm{~min})$ half-life and inhibited by its potent plasma inhibitor (PAI-1). Therefore, it does not contribute further to fibrinolysis. This serves the important physiological function of protecting hemostatic fibrin which has the same fibrin binding site and this is the main cause of bleeding by tPA[1]. Therefore, the current practice of administering tPA by an intravenous infusion is a particularly unphysiological treatment. 

010.

After fibrinolysis is initiated additional plasminogen binding sites are created which on the E-domain of fibrin [9]. There are two of them $[10,11]$. Plasminogen, on the first of these undergoes a conformational change which allows the intrinsic activity of prouPA to activate it [12]. This is followed by reciprocal activation of prouPA to its enzymatic form (tcuPA) [13], and tcuPA then activates the remaining plasminogen completing fibrinolysis.

This dual activator pathway is consistent with the modes of action of the activators since they are complementary [14] and have a synergistic lytic effect when combined [15]. This mechanism was also corroborated the finding that tPA plasminogen activation was specifically promoted by the fibrin D-domain and that by prouPA only by the fibrin E-domain [16]. This is also consistent with their complementary modes of action [14] and explains why both tPA and prouPA are required for effective lysis. It is also noteworthy that in this sequential combination tPA activates one plasminogen whereas uPA, which has two forms, activates two and is responsible for two-thirds of the fibrinolysis.

The patent trial referred in the abstract is the only published study in which the endogenous fibrinolytic paradigm of a sequential combination of the activators was tested clinically. In 101 AMI patients a mini bolus of tPA was administered to initiate fibrinolysis. In keeping with the findings that IPA was only responsible for this step, no additional tPA was given. This bolus was followed by a prouPA infusion of 90 minutes. This resulted in a complete infarct artery opening rate of $82 \%$ and an AMI mortality of $1 \%$ [17]. This compares with a $45 \%$ opening rate and a mortality of $6.3 \%$ in the best of the tPA studies (GUSTO) [18].

Not long after this trial, the company that supported it (Farmitalia) was sold to Pharmacia, which abandoned all cardiovascular drug development. Therefore, the opportunity to do a second trial with this combination was lost. Nevertheless, the patent trial results stand as a positive proof of the concept and attest to the clinical potential obtainable when the natural fibrinolytic paradigm is used in fibrinolytic therapy.

More recently, a single site mutant of prouPA has been developed which has the advantage of being five-fold more stable in plasma at therapeutic concentrations, making it much less likely to cause bleeding side effects. At the same time, it has all the other properties of native prouPA [19-24].

\section{Conclusion}

The administration of tPA alone for fibrinolysis was based on a misunderstanding and is analogous to trying to run a car on only its staring motor. tPA and prouPA have sequential and different modes of action which are complementary and gives them a synergistic lytic effect when combined. Only by using both activators can all the fibrin-bound plasminogens be activated at fibrin-specific, safe doses. This is the key to both fibrinolytic efficacy and minimization of bleeding side effects.

\section{Acknowledgements}

The author was fully responsible for this paper

\section{Conflicts of Interest}

The author is the Scientific Director of TSI, the company developing a uPA mutant for use in therapeutic fibrinolysis.

\section{References}

1. Gurewich V (2016) Therapeutic Fibrinolysis: How Efficacy and Safety Can Be Improved. J Am Coll Cardiol 68: 2099-2106.

2. Husain SS, Lipinski B, Gurewich V (1981) Rapid purification of a high-affinity plasminogen activator from human blood plasma by specific adsorption on fibrin/Celite. Proc Nat AcadSci USA 78: 4265-4269.

3. The IST-3 collaborative group (2012) The benefits and harms of intravenous thrombolysis with recombinant tissue plasminogen activator within 6 $\mathrm{h}$ of acute ischaemic stroke (the third international stroke trial [IST-3]): a randomised controlled trial. The Lancet 379: 2352-2363.

4. Boersma E, Maas ACP, Deckers JW, Simoons ML (1996) Early thrombolytic treatment in acute myocardial infarction: reappraisal of the golden hour. The Lancet 348: 771-775.

5. Schofield PM (2005) Acute myocardial infarction: the case for pre-hospital thrombolysis with or without percutaneous coronary intervention. Heart 91: 7-11.

6. Reimer KA, Vander Heide RS, Richard VJ (1993) Reperfusion in acute myocardial infarction: effect of timing and modulating factors in experimental models. Am J Cardiol 72: 13-21.

7. Voskuilen M, Vermond A, Veeneman GH, van Boom JH, Klasen EA, et al. (1987) Fibrinogen lysine residue A alpha 157 plays a crucial role in the fibrin-induced acceleration of plasminogen activation, catalyzed by tissue-type plasminogen activator. J Biol Chem 262: 5944-5946.

8. Hoylaerts M, Rijken DC, Lijnen HR, Collen D (1982) Kinetics of the activation of plasminogen by human tissue plasminogen activator. Role of fibrin. J Biol Chem 257: 2912-2919.

9. Harpel PC, Chang TS, Verderber E (1985) Tissue plasminogen activator and urokinase mediate the binding of Glu-plasminogen to plasma fibrin I. Evidence for new binding sites in plasmin-degraded fibrin I. J Biol Chem 260: 4432-4440.

10. Suenson E, Lützen O, Thorsen S (1984) Initial plasmin-degradation of fibrin as the basis of a positive feed-back mechanism in fibrinolysis. Eur $\mathbf{J}$ Biochem 140: 513-522.

11. Sun Z, Jiang Y, Ma Z, Wu H, Liu BF et al. (1997) Identification of a flexible loop region (297-313) of urokinase-type plasminogen activator, which helps determine its catalytic activity. J Biol Chem 272: 23818-23823.

12. Liu J, Gurewich V (1992) Fragment E-2 from fibrin substantially enhances pro-urokinase-induced Glu-plasminogen activation. A kinetic study using the plasmin-resistant mutant pro-urokinase Ala-158-rpro-UK. Biochemistry 31: 6311-6317.

13. Petersen LC (1997) Kinetics of reciprocal pro-urokinase/plasminogen activation. Stimulation by a template formed by the urokinase receptor bound to poly(D-lysine). Eur J Biochem 245: 316-323.

14. Pannell R, Black J, Gurewich V (1988) Complementary modes of action of tissue-type plasminogen activator and pro-urokinase by which their synergistic effect on clot lysis may be explained. J Clin Invest 81: 853-859.

15. Gurewich V, Pannell R (1987) Synergism of tissue-type plasminogen activator (t-PA) and single-chain urokinase-type plasminogen activator (scuPA) on clot lysis in vitro and a mechanism for this effect. Thromb Haemost 57: $372-373$ 
16. Liu J, Gurewich V (1991) A comparative study of the promotion of tissue plasminogen activator and pro-urokinase-induced plasminogen activation by fragments D and E-2 of fibrin. J Clin Invest 88: 2012-2017.

17. Zarich SW, Kowalchuk GJ, Weaver WD, Loscalzo J, Sassower M, et al. (1995) Sequential combination thrombolytic therapy for acute myocardial infarction: results of the pro-urokinase and t-PA enhancement of thrombolysis (PATENT) trial. J Am Coll Cardio 26: 374-379.

18. GUSTO Angiographic investigators (1993) The effects of tissue plasminogen activator, streptokinase, or both on coronary-artery patency, ventricular function, and survival after acute myocardial infarction. N England J Med 329: 1615-1622.

19. Liu J, Gurewich V (1993) A site-directed mutagenesis of pro-urokinase at the flexible loop region of active domain. Protein Engineering, Design and Selection 6: 45-46.

20. Liu JN, Tang W, Sun ZY, Kung W, Pannell R, et al. (1996) A site-directed mutagenesis of pro-urokinase which substantially reduces its intrinsic activity. Biochemistry 35: 14070-14076.
21. Liu JN, Liu JX, Liu B, Sun Z, Zuo JL, et al. (2002) Prourokinase Mutant That Induces Highly Effective Clot Lysis Without Interfering With Hemostasis. Circu Res 90: 757-763.

22. Gurewich V, Pannell R, Simmons-Byrd A, Sarmientos P, Liu JN, et al. (2006) Thrombolysis vs. bleeding from hemostatic sites by a prourokinase mutant compared with tissue plasminogen activator. J Thrombos Haemostas 4: 1559-1565.

23. Pannell R, Kung W, Gurewich V (2007) C1-inhibitor prevents non-specific plasminogen activation by a prourokinase mutant without impeding fibrinspecific fibrinolysis. J Thrombos Haemostas 5: 1047-1054.

24. Tomasi S, Sarmientos P, Giorda G, Gurewich V, Vercelli A (2011) Mutant prourokinase with adjunctive $\mathrm{C} 1$-inhibitor is an effective and safer alternative to tPA in rat stroke. PLoS One 6: 21999. 